\title{
DAYLIGHT AND URBAN MORPHOLOGY: A MODEL FOR ANALYSING THE AVERAGE ANNUAL ILLUMINATION OF RESIDENTIAL HOUSING
}

\author{
Ana Perišić, Marko Lazić, Ratko Obradović, Irena Galić
}

Original scientific paper The model proposed in this paper is based on a multi-criteria analysis of annual daylight illumination relying on the interoperability of commercially available software tools. The daylight performance of different urban morphologies is investigated by simulating and measuring real weather conditions for a specified location on two types of 3D models. The first analysis is conducted on optimized 3D models of typical urban block morphology and the second analysis is conducted on a 3D model of an existing block extracted from the corpus of the city of Novi Sad. The results are processed according to the criteria of health factors such as the minimum daylight exposure value of $190 \mathrm{~lx}$. The comparative analysis of the results showed that there is a difference between the different types of block morphologies regarding the illumination intensity for the interior spaces. The obtained values are presented in tabular form, graphic and $3 \mathrm{D}$ view.

Keywords: daylight simulation; healthy housing conditions; urban block; urban morphology

Dnevno svjetlo i urbana morfologija: Model za analizu prosječne osvijetljenosti stambenih prostora

Izvorni znanstveni članak

Model predložen u ovom radu zasnovan je na višekriterijskoj analizi godišnje dnevne osvijetljenosti uz oslanjanje na interoperabilnost više programskih alata. Performanse dnevne osvijetljenosti različith urbanih morfologija istražene su pomoću simulacije i mjerenja realnih klimatskih uvjeta za definiranu lokaciju na dva tipa 3D modela. Prva analiza izvršena je optimiziranim tipskim urbanim morfologijama bloka, druga analiza izvršena je na 3D modelu bloka koji je dio urbanog tkiva grada Novog Sada. Rezultati su obrađeni u skladu s kriterijem minimalne vrijednosti zdrave izloženosti dnevnom svijetlu u vrijednosti od 190 lx. Komparativna analiza rezultata pokazala je kako postoji razlika u intenzitetu osvijetljenja za unutrašnje prostore između različitih tipova morfologije bloka. Dobivene vrijednosti predstavljene su u obliku tablica, grafova i 3D prikaza.

Ključne riječi: simulacija dnevne osvijetljenosti; urbani blok; urbana morfologija; zdravi uvjeti stanovanja

\section{Introduction}

The utilization of new representational methods in architectural and urban design, supported by the various commercially available software tools, opens new ways for supporting the creative process in all stages of building design. The possibility of creating virtual or augmented reality, based on the available software tools and integrated development environments, becomes a challenge to domain experts as well as to software designers. Inherent complexity, embedded in real world concepts, promotes modelling and simulations as the unavoidable mechanisms for either the preventive evaluation of engineering achievements or the formulation of reengineering activities that may upgrade certain characteristics of engineered artefacts. In [1] model is broadly defined as a formal or informal representation and abstraction of anything (a real system, a proposed system, a futuristic system design, an entity, a phenomenon or an idea), while simulation is defined as the act of executing, experimenting with, or exercising a model or a set of models to achieve specific objectives. It is generally agreed that there is a strong interdependency between modelling and simulation that leads to the concept of Model Based Simulations (MBSs). Special challenges lie in the modelling and parametric simulation of space and urban blocks that enables the analysis of existing urban environment in order to gain its potential revitalization, and/or the estimation of future projects.

Throughout the history of planning and city building there were periods of time when aspects of healthy living dominated the other properties of built environment. The contemporary high-density construction approach, which may be rationally justified from the aspect of effective use of space, usually results in the lack of natural light, inadequate natural ventilation, and other phenomena that may affect the overall living conditions [2].

Despite the fact that there are several commercially available software tools that support different phenomena simulations, an integrated solution that would incorporate analytic potentials to effectively utilize the criteria of healthy living conditions in architecture and urbanism has still not been defined. Our research is focused on establishing a new criteria model that may be applied in arbitrary parametric simulation of the urban built environment.

In this article we present the implementation of a simulation based model which is aimed at the evaluation of daylighting potentials of different urban block morphology models based on the interoperable multy tool simulation framework. Two platforms of the performance aspects are described and analysed: an optimized 3D model of typical urban block morphology and an optimized 3D model of an existing block which is extracted from the corpus of the city of Novi Sad. The analysis is performed from the aspect of healthy living conditions of the built environment and daylight calculation software tools that were incorporated in the interoperable framework configuration.

The rest of the article is organized as follows: Section 2 presents the research background, Section 3 introduces the proposed simulation methodology and the configuration of multiple tools framework that has been used as a simulation hyper-tool, Section 4 presents the referent case study detailes, Section 5 contains methodology and the framework application to the real 
world urban blocks, Section 6 concludes the article while Section 7 lists the related references.

\section{The research background}

There are two main aspects that have to be discussed concerning the evaluation of the healthy living attributes of urban blocks or city: technical and medical. From the technical aspect, relying on more or less sophisticated information technology and software tools, a number of automated methods of daylight illumination calculation may be used. The representative ones are: a spreadsheet method, a method of sharing flux (flux split BRE) based on the calculations of light radiosity, Lumen Designer, the ray tracing and software solutions such as Autodesk Ecotect $^{\circledR}$ and IES VE-ware, Green building Studio ${ }^{\circledR}$, and others.

While simulating the daylight illumination of the built environment one of the most important aspects is the results accuracy of the tools used. Radiance represents a generally accepted tool in the construction industry in more than $50 \%$ of illumination analysis [3, 4]. The confirmation of the accuracy of the results obtained through Radiance may be found in the field survey presented in [5]. There are relevant comparative analyses documenting that the results obtained by the concurrent software tools, like for example Autodesk Ecotect ${ }^{\circledR}$, and the principles on which the calculations are based for Green Building Studio ${ }^{\circledR}$, did not give better results when compared to Radiance [6, 7]. That was the main reason for using Radiance as a collection of software tools, for lighting simulations in our researches.

From the medical aspect, several researchers have confirmed the significant impact of daylight on the physical and mental health, psychological state and work productivity of humans. The lack of sunlight causes serious vitamin $D$ deficiency which causes a range of disease states [8]. The impact on the recovery of patients and setting the limits of minimum intensity of daylight was analysed by Joarder et al. [9, 10]. By measuring the length of hospital stay after surgical intervention, in relation to exposure to sunlight in the hospital room, the conclusion was made that the stay is reduced by 7,3 hours for every $100 \mathrm{~lx}$ added illumination in the room. The analysis of the natural light influence [11] showed that the presence of light greater than $1000 \mathrm{~lx}$ contributes to the reduction of variable mood among workers (especially for those who suffer from seasonal depression) and reduces the level of aggression and violent behaviour at work as opposed to staying in areas that are less illuminated. In Beauchemi et al. and Ravindran et al. the authors clearly demonstrate a strong correlation between the influence of daylight and the recovery speed of patients suffering from depressive states $[12,13]$.

There are limited statistically significant and welldocumented scientific proofs of the exact daylight illumination intensity needed for establishing sustainable healthy condition in urban environment [14]. The exact boundaries of sufficient illumination are important for this study. Some methods suggest establishing upper limits when high intensity lighting creates discomfort $[15,16$, 17]. This approach is not included in this paper, because the increased amount of light can be reduced in the interior with classic windows. According to Joarder and Price [9, 18] lower limit for the illumination of the interior space can be set. Their study indicates that patients staying in the room with less than $190 \mathrm{~lx}$ of lighting, stayed the maximum length of time according to the postoperative hospital stays statistics. The results of this research confirm that proper day light illumination may speed up patients' recovery process. The same results were confirmed by other independent studies [19, 20]. In this paper the results of previous medical researches implemented in the analysis are not meant for verifying only the living conditions of hospital environments, but also as a preventive health measure for all living spaces.

These results had the main impact on determining the threshold values used while performing the simulations on the proposed model. The hypothetical minimal threshold value for the healthy level of daylight illumination was set to $190 \mathrm{~lx}$.

\section{Discussion}

The model is based on previous researches in the field of medicine and computer daylight simulation for illumination intensity, with an emphasis on the form of data representation. The results are displayed in three forms: in the form of table, in the form of chart and in 3D geometrical view. The software analysed in the field does not offer solution for getting the results from the aspect of healthy living conditions and in all three forms of display.

There were several challenging problems that we had to address prior to proper configuration of the cooperating framework. The results obtained using Radiance software, display the illumination of the block envelopes, but not the daylight conditions in the interiors of built structures. The solution for the problem could be in the form of $3 \mathrm{D}$ modelling the entire interior of the analysed structures in the block. In the case of analysing a city block, this solution is not optimal, due to the size of the analysed area. Given that the simulation of the exact internal structure of the block is very difficult and time consuming, the simulation has been done on the model of the test room.

The aspect of time is an important factor. For that purpose the authors defined the framework for annual seasonal daylight fluctuation. Other shorter time intervals are not suitable for analysis, because the most important factor for daylight illumination depends on the Sun altitude and azimuth, based on annual cycles.

These aspects are developed in details and modified in the proposed methodology.

\section{The proposed methodology}

In the first phase of the model, daylight simulation for imported 3D geometry is performed in Radiance software. The second phase involves the interpretation of the results in view of their relation to the minimum illumination intensity (Fig. 1).

The first step of the analysis consists of a simulation performed on different types of block morphology while the second one is focused on analysing the methodology efficiency when applied on the model created from 
geometry belonging to the real built environment. Three types of urban blocks are created based on the existing morphology of urban blocks in the city of Novi Sad.

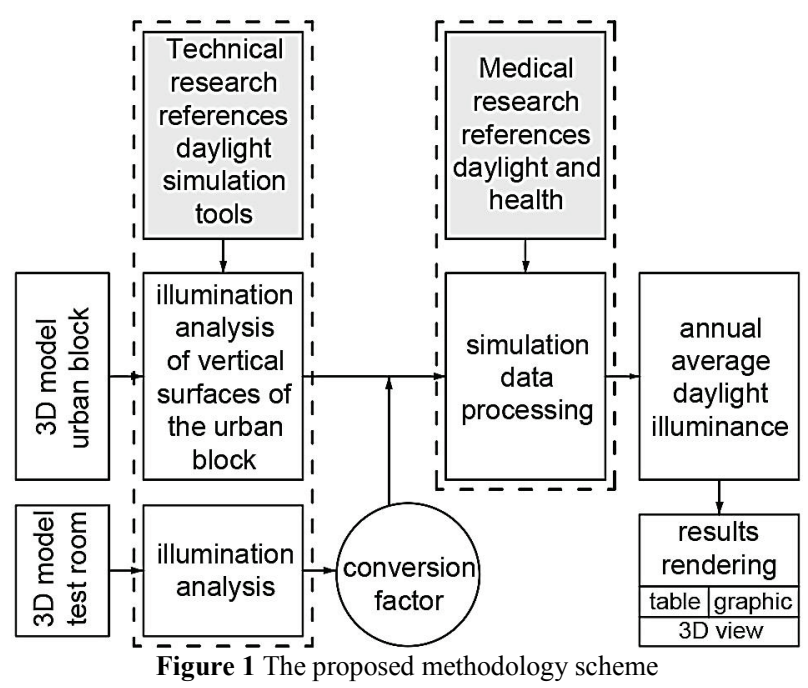

In order to confirm the methodology described in the theoretical part of the paper, we have analysed the idealized forms of blocks, uniformed in terms of the dimensions of the plot. The main goal was to detect those places on the facade that are not suitable for the windows placement according to the defined minimal illumination level. Only the vertical surfaces of buildings are analysed because they represent the building facades of the urban block geometry.

The vertical surfaces of the block are divided into a grid of square polygons. Polygon dimensions depend on the complexity and defined fidelity of the required analysis. In the simulation performed in this paper two raster polygon $3 \mathrm{D}$ models were used, with measures $5 \times 5$ $\mathrm{m}$ (for the analysis performed on three blocks) and $3 \times 3$ $\mathrm{m}$ (for the analysis performed on the block Liman III in Novi Sad).

The analysis is based on including the actual climate data for the location where the simulation is performed, in the city of Novi Sad, Serbia. The optimization based on the utilization of four strategically chosen days of the year $\left(21^{\text {st }}\right.$ March, 22 $2^{\text {nd }}$ June, $23^{\text {rd }}$ September and $21^{\text {st }}$ December) dramatically reduced the calculation time thus enabling the real time visualization of the calculated data. Because of the Sun movement during the day the calculations are performed at one hour interval in the period between $8 \mathrm{~h}$ and $17 \mathrm{~h}$. That makes a total of 40 analyses (10 each day, 4 days a year) for each area of the analysed urban block.

The method used for the simulation on the block created from geometry and based on real built environment involves a complex and detailed approach where 20 days uniformly distributed during the year are analysed. The days are chosen in relation to the four mentioned weather extreme dates, and the remaining 16 are interpolated between them. Two hundred analyses are performed (10 per day during 20 days).

The amount of light received by the surface of the facade, is, in most cases, sufficient to meet the conditions for healthy living. This is not the case with the interior space, because some of the light is lost due to various factors. The results may vary depending on the dimensions of the windows, Sun's azimuth and elevation angles, the orientation of the windows and the size of the room. Some of sunlight intensity is lost due to various factors like the density of glass, reflection, etc. [21]. The simulation has been done on the model of the test room. The dimension of the room used in the model is $4,40 \times$ 4,40 m, which makes the floor surface area of $19,36 \mathrm{~m}^{2}$ and corresponds to the standard dimensions of a living room. The standard dimensions are based on the minimum size of a living room in a four-room apartment, which is $19 \mathrm{~m}^{2}$ as defined by state regulations [22]. The reason for analysing rooms of this size is the fact that in the Novi Sad area $90,46 \%$ of all apartments have four rooms or fewer [23]. The ceiling height is set to $2,70 \mathrm{~m}$. The window is in the middle of the wall, and has the dimensions of $1,60 \times 1,35 \mathrm{~m}$ (Fig. 2). The room type that was used in the experimental evaluation within the model proposed here was selected as an illustrative example, which is suitable for simulation processes and can be changed in relation to the location, regulations in the local area and the type of room. All surface reflection properties are uniform, simulating walls painted in white.

The amount of light in the room varies according to the distance from the light source (window). Only one result is measured from the marker surface. The marker is a horizontal surface with dimensions $0,20 \times 0,20 \mathrm{~m}$, at a height of $0,70 \mathrm{~m}$ from the floor, placed in the middle of the room (Fig. 2). If the criterion for the minimum daylight illumination of the marker is met, the room is considered to be sufficiently illuminated.

The model defines the conversion factor as the relationship between the external illumination measured on the facade and interior illumination measured on the marker surface, Eq. (1).

$$
E_{\mathrm{i}}=F \cdot E_{\mathrm{e}} .
$$

In Eq. (1) $E_{\mathrm{i}}$ is the interior illuminance at a specific point on marker surface (lx), $F$ is the conversion factor, and $E_{\mathrm{e}}$ is the exterior vertical illuminance at the window (lx).
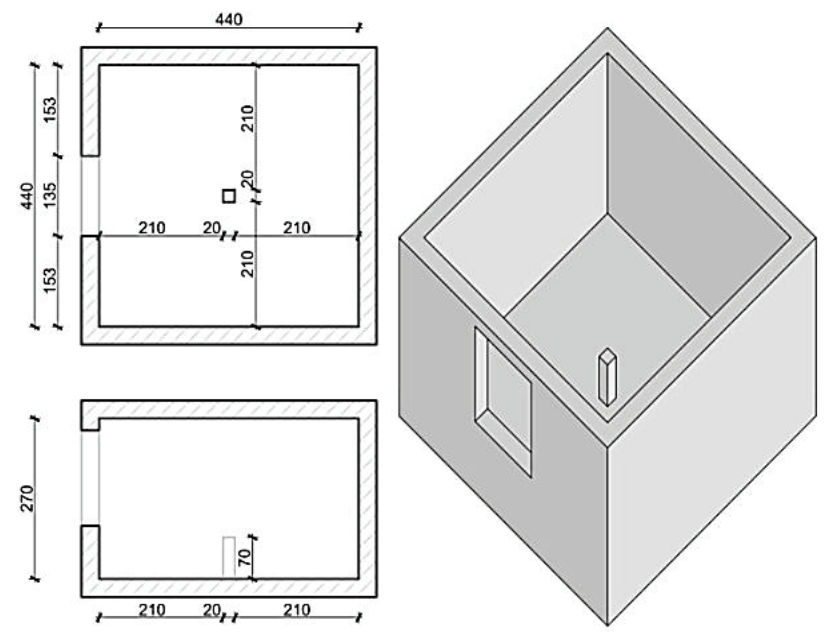

Figure 2 Test room. Left up - floor plan, left down - section, right - axonometric view

The conversion factors for all cases are determined by simulating the daylight illumination on the specific 
geographical location and they are applied to all objects in the same location. This factor can depend on the following parameters: room dimensions, dimensions of the windows on the façade, distance between the window and the marker used to measure the illumination, orientation of the window in the room, light reflection from the room walls, floor and ceiling as well as direct or indirect type of lighting.

The illumination can be direct or indirect. In these two situations different factors of illumination are present, and before final results are rendered it is necessary to analyse whether the surfaces are directly or indirectly exposed to sunlight during the year. Whether the surface is exposed to direct sunlight is determined by a special simulation where each individual mesh is examined by placing lines which represent rays of light from the observed surface to the Sun, with the source of light (the Sun) adjusted by geo-location, date, and time. If a collision with one of the meshes of the 3D model is detected, the light source is considered to be indirect.

The simulations are performed on a test room and the data are collected according to orientation in relation to eight cardinal and inter-cardinal directions for all the observed dates and times. The relationship between the illumination intensity on the façade and at the marker in the room is calculated for each direction, date and time independently, and assumed to be constant. Using equation (1) façade daylight illumination can be transformed into interior spaces illumination. Daylight illumination results produced by the simulation process on $3 \mathrm{D}$ models are multiplied by a conversion factor for each mesh. The utilization of the proposed methodology excludes the development of interior 3D models. The next step is determining the number of hours during which each observed façade surface has the illumination intensity higher than the determined threshold value of 190 lx. The results are rendered for each day indicating the number of hours that satisfy the criterion, and the average number of targeted illumination hours is calculated at the annual level

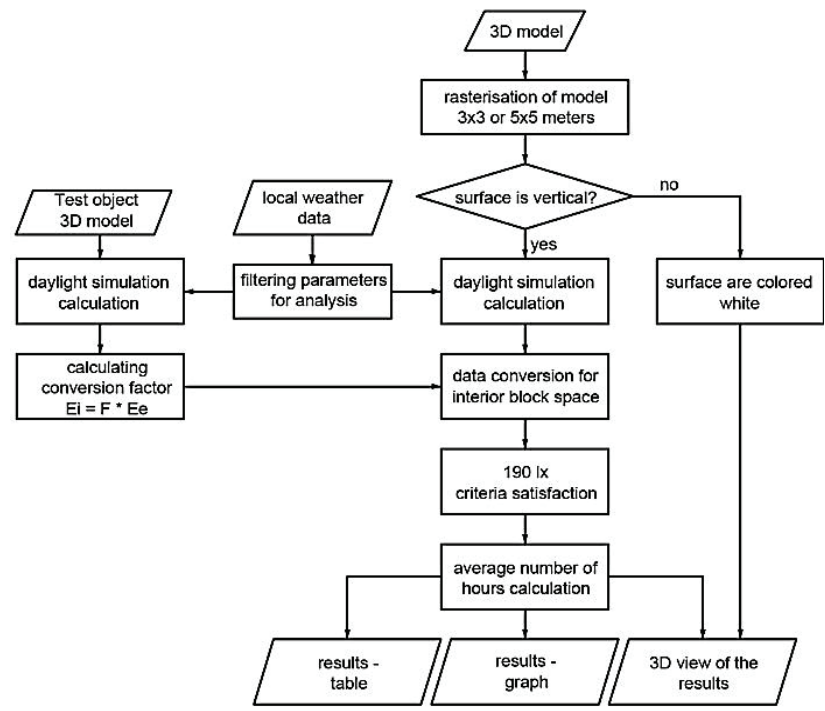

Figure 3 Process tree of the used methodology

In Fig. 3, the process algorithm describing the proposed methodology is presented. The inputs are local weather data and 3D geometries of the new urban block and the test room.

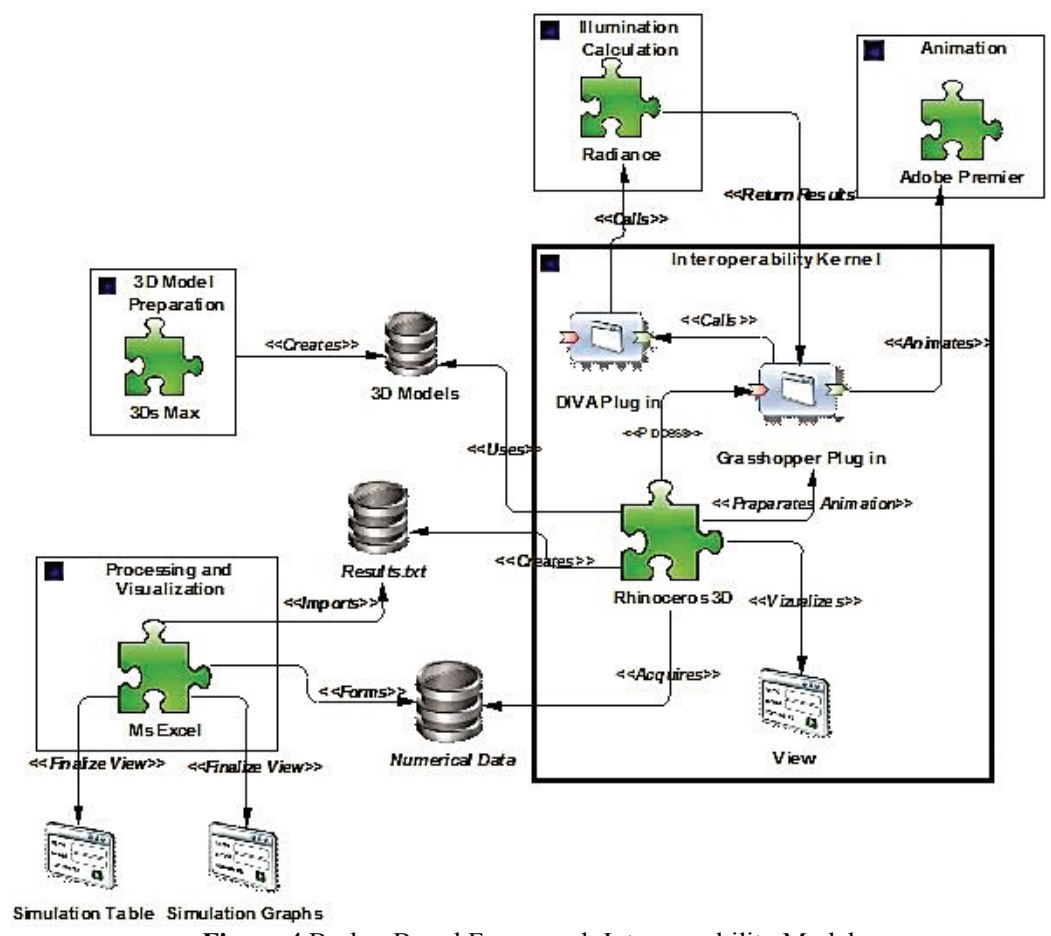

Figure 4 Broker Based Framework Interoperability Model

The processes of calculation and manipulation of data are in the middle of the algorithm, and the export results are presented in tabular form, graphics and through 3D views. The $3 \mathrm{D}$ view can inform the designer of potential problems in the early stage of the design without the need for a detailed analysis. The process for daily average values of illumination can be animated as a set of 
different surface representations in relation to the criteria defined by the model displaying illumination intensities.

Fig. 4 presents the interoperability model of multiple tools framework used for the daylight simulation of urban blocks. The cooperation is based on an orchestration framework model based on broker orchestrator introduced in [24]. The Interoperability kernel used in the orchestrating framework relies on the Radiance and DIVA plug-in for Rhinoceros $3 D^{\circledR}$ as part of the simulation conducted for this study, and Grasshopper plug-in for Rhinoceros $3 D^{\circledR}$ used for the majority of process automation tasks. Outside the interoperability kernel there are four independent software tools whose functionality is orchestrated by the interoperability kernel. The information exchanged with the software Autodesk 3D studio Max ${ }^{\circledR}$ is importing data. Software Radiance data is analysed and returned to the Rhinoceros $3 D^{\circledR}$ software. Some data which need to be calculated are processed through MS Excel ${ }^{\mathbb{R}}$, where they can be directly read. 3D geometry data can be presented through animations by exporting images to Adobe Premier ${ }^{\circledR}$.

\section{Referent case study}

The simulations are performed on different types of block morphology based on the described methodology. Three blocks corresponding to the different types of urban blocks in Novi Sad have been modelled as 3D representations. The blocks are labelled $\mathrm{A}, \mathrm{B}$ and $\mathrm{C}$, with the following characteristics:

- Block A - block type with single-family houses. This type of morphology appears in the central area of the city. The volume occupied by structures is $50000 \mathrm{~m}^{3}$ and is designed for high density housing, about 700 inhabitants per hectare. The rule for maximum allowed height is Ground floor +2 stories. Percentage of lot occupancy is $75 \%$;
- $\quad$ Block B - block with tower type multi-family houses. The volume occupied by structures is $50000 \mathrm{~m}^{3}$ and is designed for high density housing, about 700 inhabitants per hectare. The rule for maximum allowed height is Ground floor +15 stories. Percentage of lot occupancy is $10 \%$; and

- Blok C - high-density edge block type. The volume occupied by structures is $100000 \mathrm{~m}^{3}$ and is designed for very high density housing, about 1400 inhabitants per hectare. The rule for maximum allowed height is Ground floor +7 stories. Percentage of lot occupancy is $60 \%$.

The simulation has been performed for the four representative days. Lighting conditions are used according to the block location in the city of Novi Sad. The process is conducted according to the previously described methodology.

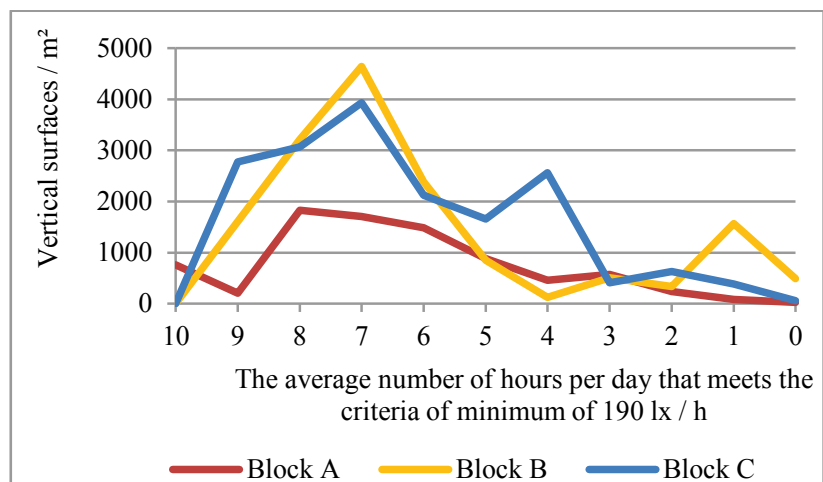

Figure 5 Graph results of daylight illumination on 3D model for blocks $\mathrm{A}, \mathrm{B}$ and $\mathrm{C}$

Tab. 1 shows the numerical results for blocks A, B and $\mathrm{C}$ indicating the average daily illumination of vertical surfaces and the percentages depending on the satisfied criteria.

Table 1 The result of the daylight simulation for blocks A, B and C depending on the criteria satisfied

\begin{tabular}{|c|c|c|c|c|c|c|}
\hline \multirow{2}{*}{$\begin{array}{l}\text { The average number of } \\
\text { hours per day that meets } \\
\text { the criteria of minimum of } \\
1901 \mathrm{x} / \mathrm{h}\end{array}$} & \multicolumn{2}{|c|}{ Block A } & \multicolumn{2}{|c|}{ Block B } & \multicolumn{2}{|c|}{ Block C } \\
\hline & $\begin{array}{c}\text { Vertical } \\
\text { surfaces } / \mathrm{m}^{2}\end{array}$ & $\begin{array}{l}\text { Illumination of } \\
\text { surfaces } / \%\end{array}$ & $\begin{array}{c}\text { Vertical } \\
\text { surfaces / } \mathrm{m}^{2}\end{array}$ & $\begin{array}{l}\text { Illumination of } \\
\text { surfaces / \% }\end{array}$ & $\begin{array}{c}\text { Vertical } \\
\text { surfaces / } \mathrm{m}^{2}\end{array}$ & $\begin{array}{l}\text { Illumination of } \\
\text { surfaces / \% }\end{array}$ \\
\hline 10 & 763 & 9 & 0 & 0 & 0 & 0 \\
\hline 9 & 207 & 3 & 1613 & 10 & 2777 & 16 \\
\hline 8 & 1832 & 22 & 3216 & 20 & 3066 & 17 \\
\hline 7 & 1711 & 21 & 4642 & 30 & 3929 & 22 \\
\hline 6 & 1487 & 18 & 2384 & 15 & 2126 & 12 \\
\hline 5 & 886 & 11 & 849 & 5 & 1656 & 9 \\
\hline 4 & 463 & 6 & 123 & 1 & 2559 & 15 \\
\hline 3 & 578 & 7 & 505 & 3 & 415 & 2 \\
\hline 2 & 243 & 3 & 337 & 2 & 635 & 4 \\
\hline 1 & 82 & 1 & 1570 & 10 & 389 & 2 \\
\hline 0 & 26 & 0 & 494 & 3 & 58 & 0 \\
\hline
\end{tabular}

The results presented in Fig. 5 and Tab. 1 confirm that these different types of blocks in the same climate conditions have significantly different levels of daylight illumination. The plots of blocks A, B and C are identical, which leads to the conclusion that the morphological characteristics of structures and their arrangement represent the factor which affects the illumination. According to the results presented in Tab. 1, the analysed blocks have a different results distribution. The sevenhour illumination is found in a large number of areas and in Fig. 5 there is the graph peek located $(22 \div 30 \%$ of the surface of each monitored block have seven-hour result).

Block B has the largest extreme illuminated vertical surfaces in the aspect of the set criteria. Approximately 60 $\%$ of the block B is illuminated for seven hours or more on average during one day, and the percentage of the 
surface with an average brightness of one hour or less is $13 \%$. It is a high value in relation to the other two blocks that differ by $1 \div 2 \%$. There is a similar percentage of daylight illumination in the case of the blocks $\mathrm{A}$ and $\mathrm{C}$, presented in Tab. 1. In both cases the average annual daylight illumination is higher than six hours a day for 55 $\%$ of the analysed surfaces. The results in Fig. 5 show that block $\mathrm{C}$, in comparison to block $\mathrm{A}$, has a greater number of surfaces illuminated for more than six hours a day. It is because block $\mathrm{C}$ has a bigger built surface than block $\mathrm{A}$.

Fig. 6 represents the results of the daylight illumination in 3D geometry views. Using these views the designer may quickly reach the decision concerning room placement/displacement based on the facade illumination data. White surfaces suggest a good place for the living room window placement, while the black parts suggest the place that should be avoided if it is technically possible or justifiable.

Places with darker grey tones, presented in Fig. 6, do not assume that placing the window in that area is contrary to the logic of architectural design. It merely states that rooms with windows placed in these areas of the façade are not medically suitable for a long stay during the day.

Alternatively, the suitability level may be raised if window size is increased, dimensions of the room are reduced, or if some other interventions that increase the amount of illumination in the interior are performed.
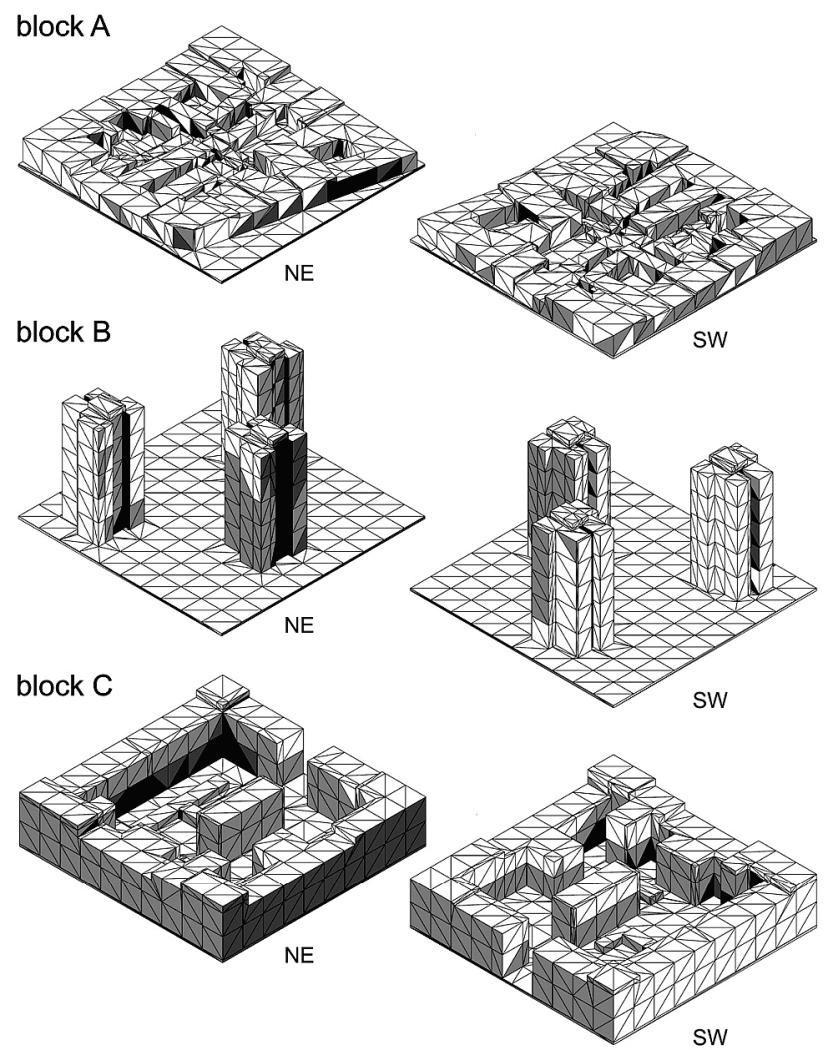

Figure $63 \mathrm{D}$ graphic view of results for three blocks (NE - northeast, SW -southwest)

\section{Analysis of three towers in Liman III urban block}

The additional simulation has been performed on a 3D model of the existing urban block in Liman III district of Novi Sad. Three free-standing residential buildings are analysed. In order to reduce the calculation time, the 3D model geometry is reduced by ignoring all parts of the outer shell extending beyond the facade by less than $1 \mathrm{~m}$. In addition, details of the façade, greenery, and ephemeral structures are excluded too.

The simulation was performed for the resolution of 20 days, thereby increasing the level of detail in the results, but also significantly increasing the time for getting the results. The surrounding buildings were included in the analysis. Tab. 2 represents the numerical results of daylight illumination of vertical surfaces of three buildings in the block Liman III, giving the percentage of satisfaction of the criteria displayed in the model.

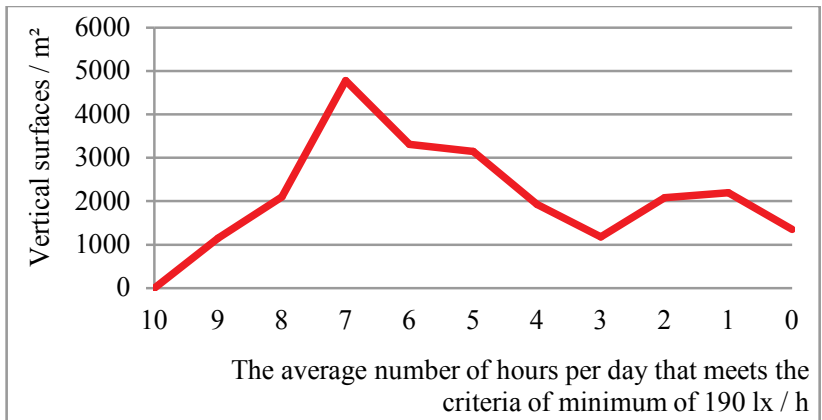

Figure 7 Graph results of daylight illumination on 3D model of Liman III, Novi Sad

Table 2 The result of the daylight simulation for three towers in Liman III urban block, Novi Sad

\begin{tabular}{|c|c|c|}
\hline $\begin{array}{c}\text { The average number of hours } \\
\text { per day that meets the criteria } \\
\text { of minimum of } 190 \mathrm{~lx} / \mathrm{h}\end{array}$ & $\begin{array}{c}\text { Vertical } \\
\text { surfaces } / \mathrm{m}^{2}\end{array}$ & $\begin{array}{c}\text { Illumination of } \\
\text { surfaces } / \%\end{array}$ \\
\hline 10 & 0 & 0 \\
\hline 9 & 1147 & 5 \\
\hline 8 & 2097 & 9 \\
\hline 7 & 4782 & 21 \\
\hline 6 & 3310 & 14 \\
\hline 5 & 3143 & 14 \\
\hline 4 & 1923 & 8 \\
\hline 3 & 1173 & 5 \\
\hline 2 & 2077 & 9 \\
\hline 1 & 2195 & 9 \\
\hline 0 & 1346 & 6 \\
\hline
\end{tabular}

The results presented in Tab. 2 and Fig. 7 show that the majority of surfaces analyzed by the average number of lighted hours during the day have seven hours of natural light, which is also present in the analysis that was performed on the blocks A, B and C.

In Fig. 8, the results are displayed as gray scale image for three towers in the Liman III district. The graph shows the influence of the surrounding buildings, which are included in the simulation of daylight ilumination of the façade of the towers. The effect of the environment can be seen in the parts of the towers that are closest to the surrounding buildings. The influence of the environment is an important factor, and it should be taken into account when analyzing the morphology of urban structures.

The influence of building orientation is noticable on the dark surfaces appearing in the north parts of the buildings. The surfaces facing north show suboptimal results. The ground floor apartments are the most affected 
because they are overshadowed by the surrounding buildings which reduce their daylight illumination.

The results of the simulation of Liman III block and those of block B are analysed and similar pattern has been noticed.

The overlapped results are shown in Fig. 9 and it can be seen that the displacement of extreme values of illuminated surface is similar, but the block modelled without the environmental influence exhibits better results. In this case, the main impact is due to the structures orientation which is different for the two analysed blocks (see Figs. 6 and 8).
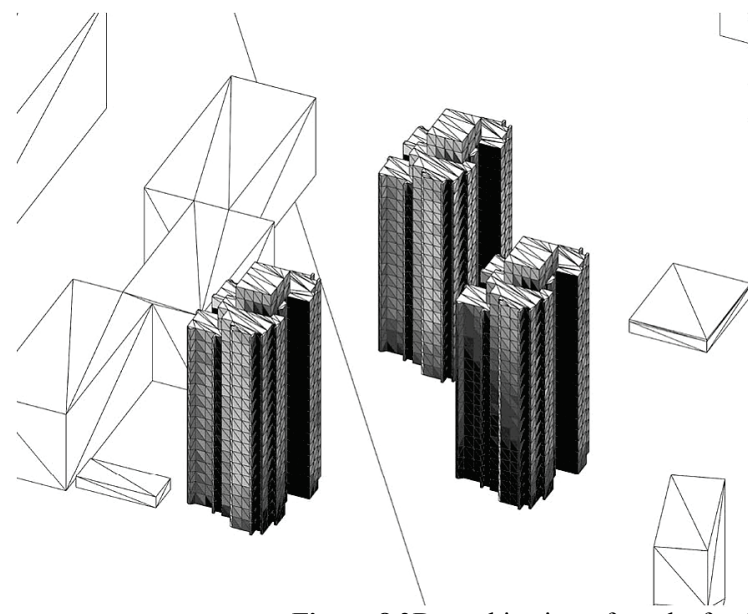

Figure 8 3D graphic view of results for three towers

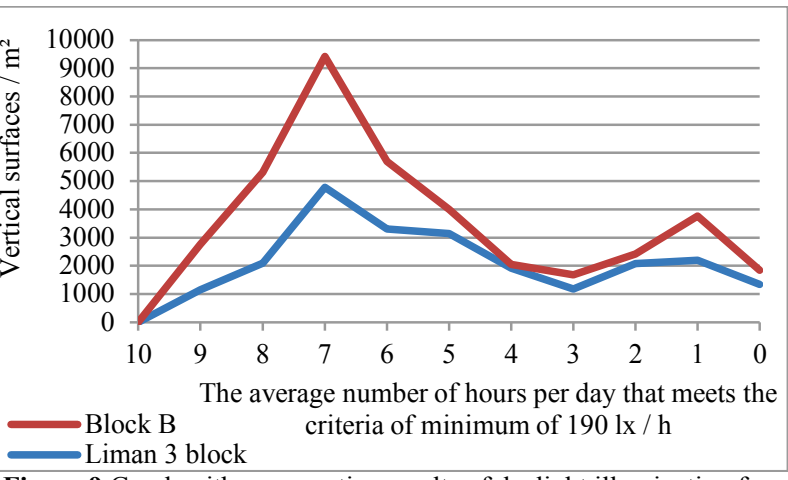

Figure 9 Graph with comparative results of daylight illumination for block B and three towers block in Liman III

The results are not significantly different for the two analysed blocks which are modelled with different accuracy and where simulation is performed on different number of days. More optimized method used on blocks $\mathrm{A}, \mathrm{B}$ and $\mathrm{C}$ may be utilized in the case of complex urban morphology and in the analysis of larger built urban areas in order to obtain the results faster while still retaining tolerable level of accuracy.

\section{Conclusion}

In this paper the aspect of healthy living conditions in the context of urban planning and reconstruction is analysed with respect to using software tools for daylight simulation. The proposed methodology relies on optimized multi-factorial analysis of daylight illumination that is extrapolated for the whole year. Three different block types without surrounding buildings and one real block extracted from the city of Novi Sad environment were simulated. The results are presented in the forms that aid the comparative analysis (tables, graphics, and 3D model views) in order to determine the optimal solution based on the proposed methodology and multiple tools cooperation framework.

It is also possible, in an early stage of planning and decision-making, to obtain the information on how the changes in the morphology of the block may affect the parts of the block, the structures inside the block and the surrounding structures.

Table and graph representations of the results of the vertical surfaces illumination enable the numerical values to be compared while $3 \mathrm{D}$ views allow quick identification of problem areas and provide enough information for improving and solving healthy living problems that may appear during the design, reconstruction or upgrade of built environment.

Using model based simulations to improve living conditions in urban environment has several directions for future development. It is possible to use the proposed methodology and the software tools interoperability principles to examine the already built urban blocks and thus enable the creation of data repository that would aid easier interpretation of future simulation results. Also, it is necessary to expand the simulation aspect of lighting to consider other important elements of healthy living such as, for example, natural ventilation. One of the main research directions is the superposition of the results obtained in areas such as daylight illumination and natural ventilation to create a multidimensional model of healthy living parameters. This would enable a multidimensional analysis of urban space model at the early stages of design.

\section{References}

[1] Sokolowski J. A.; Banks, C. M. (editors). Modeling and Simulation Fundamentals: Theoretical Underpinnings and Practical Domains. John Wiley \& Sons, Inc., 2010.

[2] Boyce, P.; Hunter, C.; Howlett, O. The benefits of daylight through windows. Rensselaer Polytechnic Institute, Troy, New York, 2003. 
[3] Reinhart, C. F.; Marilyne, A. Development and validation of a Radiance model for a translucent panel. // Energy and Buildings. $\quad 38,7$ (2006), pp. 890-904. DOI: 10.1016/j.enbuild.2006.03.006

[4] Vangimalla, P. R.; Olbina, S. J.; Issa, R. R.; Hinze, J. Validation of Autodesk Ecotect accuracy for thermal and daylighting simulations. // Proceedings of the IEEE World Simulation Conference (WSC) / Phoenix, AZ, 2011, pp. 3383-3394. DOI: 10.1109/wsc.2011.6148034

[5] Reinhart, C. F.; Walkenhorst, O. Dynamic RADIANCEbased Daylight Simulations for a full-scale Test Office with outer Venetian Blinds. // Energy \& Buildings. 33, 7(2001), pp. 683-697. DOI: 10.1016/S0378-7788(01)00058-5

[6] Ibarra, D.; Reinhart, C. F. Daylight factor simulations How close do simulation beginners 'really' get? // Proceeding of the Building Simulation Conference / Glasgow, 2009, pp. 196-203.

[7] Reeves, T.; Olbina, S.; Issa, R. Validation of building energy modeling tools: Ecotect, Green building studio and IES-VE. // Proceedings of the Winter Simulation Conference / Berlin, 2012, pp. 52.

[8] Boubekri, M. Daylighting, architecture and health. Elsevier, Oxford, 2008.

[9] Joarder, A. R.; Price, A. D. F. Impact of daylight illumination on reducing patient length of stay in hospital after coronary artery bypass graft surgery. // Lighting Research \& Technology. 45, 4(2013), pp. 435-449. DOI: $10.1177 / 1477153512455940$

[10] Joarder, M. A. R.; Price, A. D. F.; Mourshed, M. M. Impact of daylight on open heart surgery patients: an evidence based study necessary for therapeutic daylighting design. // Proceedings of the 6th World Congress on Design and Health / Singapore, 2009.

[11] Aan Het Rot, M.; Moskowitz, D. S.; Young, S. N. Exposure to bright light is associated with positive social interaction and good mood over short time periods: A naturalistic study in mildly seasonal people. // Journal of psychiatric research. 42, 4(2008), $\quad$ pp. 311-319. DOl: 10.1016/j.jpsychires.2006.11.010

[12] Beauchemin, K. M.; Hays, P. Sunny Hospital Rooms Expedite Recovery from Severe and Refractory Depressions. // Journal of Affective Disorders. 40, 12(1996), pp. 49-51. DOI: 10.1016/0165-0327(96)00040-7

[13] Ravindran, A. V.; Lam, R. W.; Filteau, M. J.; Lespérance, F.; Kennedy, S. H.; Parikh, S. V.; Patten, S. B. Canadian Network for Mood and Anxiety Treatments (CANMAT): Clinical guidelines for the management of major depressive disorder in adults.: V. Complementary and alternative medicine treatments. // Journal of Affective Disorders. 117, 1(2009), pp. S54-S64. DOI: 10.1016/j.jad.2009.06.040

[14] Aries, M. B. C.; Aarts, M. P. J.; van Hoof, J. Daylight and health: A review of the evidence and consequences for the built environment. // Lighting Research and Technology. 47, 1(2015), pp. 6-27. DOl: 10.1177/1477153513509258

[15] Nabil, A.; Mardaljevic, J. Useful daylight illuminances: a replacement for daylight factors. // Energy and Buildings. 38, 7(2006), pp. 905-913. DOI: 10.1016/j.enbuild.2006.03.013

[16] Andersen, M.; Kleindienst, S.; Yi, L.; Lee, J.; Bodart, M.; Cutler, B. An intuitive daylighting performance analysis and optimization approach. // Building Research \& Information. 36, 6(2008), pp. 593-607. DOI: 10.1080/09613210802243159

[17] Andersen, M.; Guillemin, A.; Ámundadóttir, M. L.; Rockcastle, S. F. Beyond illumination: An interactive simulation framework for non-visual and perceptual aspects of daylighting performance. // Proceedings of the 13th International Conference of the International Building Performance Simulation Association / Chambéry, France, 2013.
[18] Joarder, M. A. R.; Price, A. D. F. Therapeutic Daylight for Hospital Patients: A Search for the Benchmarks. // European Conference on Design for Health / Sheffield, UK, 2011, pp. $169-174$

[19] Pechacek, C. S.; Andersen, M.; Lockley, S. W. Preliminary Method for Prospective Analysis of the Circadian Efficacy of Daylight with Applications to Healthcare Architecture. // LEUKOS. $\quad 5, \quad 1(2008), \quad$ pp. 1-26. DOI: 15502724.2008.10747625

[20] Gochenour, S. J.; Andersen M. Circadian Effects of Daylighting in a Residential Environment// Proceedings of the Int. conference Lux Europa / Istambul, 2009.

[21] Grondzik, W. T.; Kwok, A. G.; Stein, B.; Reynolds, J. S. Mechanical and electrical equipment for buildings. John Wiley \& Sons. 2011.

[22] Pravilnik o uslovima i normativima za projektovanje stambenih zgrada i stanova, Službeni glasnik RS br. 58/2012. URL: http://www.pravno-informacioni-sistem.rs/ SlGlasnikPortal/pages/home. $x$ tml; ;sessionid $=7534 \mathrm{D} 5 \mathrm{CB} 3$ E18A0DDF8F14C553404B918 (25.03.2015).

[23] Dwellings for Permanent Habitation According to the Number of Rooms and the Floor Space (Book 23), 2011 Census of Population, Households and Dwellings in the Republic of Serbia, 2011. URL: http://www.popis2011.stat.rs/ (25.03.2015)

[24] Perišić, A.; Lazić, M.; Perišić, B.; Obradović, R. A Smart House Environment: The System of Systems Approach to Model Driven Simulation of Building (House) Attributes. // Proceedings of the Int. IEEE conference on Consumer Electronics / Novi Sad, Serbia, 2015.

\section{Authors' addresses}

Ana Perišić, M.Sc., teaching assistant, PhD student

University of Novi Sad,

Faculty of Technical Sciences,

Trg Dositeja Obradovica 6

21000 Novi Sad, Serbia

E-mail: anaperisic@uns.ac.rs

Marko Lazić, M. Sc., teaching assistant, PhD student

University of Novi Sad,

Faculty of Technical Sciences,

Trg Dositeja Obradovica 6

21000 Novi Sad, Serbia

E-mail: lazic.m@uns.ac.rs

\section{Ratko Obradović, PhD, Full Professor}

University of Novi Sad,

Faculty of Technical Sciences,

Trg Dositeja Obradovica 6

21000 Novi Sad, Serbia

E-mail: obrad_r@uns.ac.rs

Irena Galić, PhD, Assistant Professor

J. J. Strossmayer University of Osijek

Faculty of Electrical Engineering, Computer Science and Information Technology Osijek

Kneza Trpimira 2B

31000 Osijek, Croatia

E-mail: irena@etfos.hr 